\title{
Design of storm water drainage for an estate at epe in Lagos state, Nigeria
}

\begin{abstract}
The research was intended to design facilities to manage storm water for a new estate, and the scope is to determine the possible flood extent using the rational method and then provide the flows that each sewer is required to be designed to carry in order to properly drain the estate in the event of rainfall storm. The estate is located on 20 hectares of land along Lekki Express Freeway between Lagos and Epe. There's a bridge located to the north of the estate that drains the estate and the adjourning regions. The site is generally well drained, draining from South to North and East to West. The estate is a sub-catchment of a bigger catchment area that drains partly as a river that flows into the estate through its western boundary on its way to the bridge outlet to the north western section of the estate. The total catchment area contributing to flow within the estate amounts to $214335.80 \mathrm{~m}^{2}$ while the total catchment area contributing to flows within the estate and those flowing through the estate to the bridge and towards the north of the estate amount to $234955.80 \mathrm{~m}^{2}$. Gumbel Extreme Value Distribution was used to determine the Intensity Duration Frequency (IDF) was gotten and the rainfall intensities for the shortest duration (15minutes) for various return periods of $5,10,50$, and 100 years were gotten and flow then determined that will feed each sewer produced on the site. The flood levels on the estate fence and at the adjacent bridge were also determined for 30-year Return Period through interpolation on the IDF curve to be $4.85 \mathrm{~m}$ and $5.340 \mathrm{~m}$ with the bench mark being $3.39 \mathrm{~m}$ taken from the bridge.
\end{abstract}

Keywords: storm water, extreme rainfall, frequency, catchment area, sub-catchment lekki, Lagos

\section{Introduction}

\section{Background of the study}

When rain falls, it covers the entire land area where it falls. Portion of the water infiltrates the underlying soil depending on its nature while the rest flows as surface runoff with slope and gravity. These runoff causes flood if not properly taken care of. Facilities are designed to cater for this flood. The need arose to provide facilities to manage storm water for a new estate. The estate is located on 20 hectares of land along Lekki Express Freeway between Lagos and Epe. It is bounded by the Lekki Express Freeway to the North, a welldeveloped (tarred) road to the East and partly undeveloped land mass and partly developed land mass to the West. Behind the estate to the south is an already developed land. A bridge on the Lekki Express Way drains the estate and the adjourning regions. It is located to the north of the estate.

\section{Topography}

The site is generally well drained, draining from South to North and East to West. There is depression to the north western portion of the site where water collects as a pool even in the dry season. The water table is observable on the estate fence on the side of the bridge. It was noted and taken as bench mark.

\section{Catchment boundaries and overland flow}

The estate is a sub-catchment of a bigger catchment area that drains partly, as a river that flows into the estate through its western boundary on its way to the bridge outlet to the north western section of the estate depicts collection from other sub-catchments. The total catchment area contributing to flow within the estate amounts to $214335.80 \mathrm{~m}^{2}$ while the total catchment area contributing to flows within the estate and those flowing through the estate to the bridge
Volume 2 Issue 4 - 2018

\author{
Oyegoke SO,Adebanjo AS \\ Department of Civil Engineering, Afe Babalola University, Nigeria
}

Correspondence: Adebanjo AS, Department of Civil Engineering, Afe Babalola University, Ado Ekiti, Ekiti State, Nigeria, Email soyegoke@gmail.com

Received: February 28, 2018 | Published: August 06, 2018 and towards the north of the estate amount to $234955.80 \mathrm{~m}^{2}$. The area photograph, Figure 1, Figure 2 and drawings at Figures 3, Figure 4 show the areas that contribute to the storm water flow passing through the estate to the adjourning bridge outlet to the north western section of the estate.

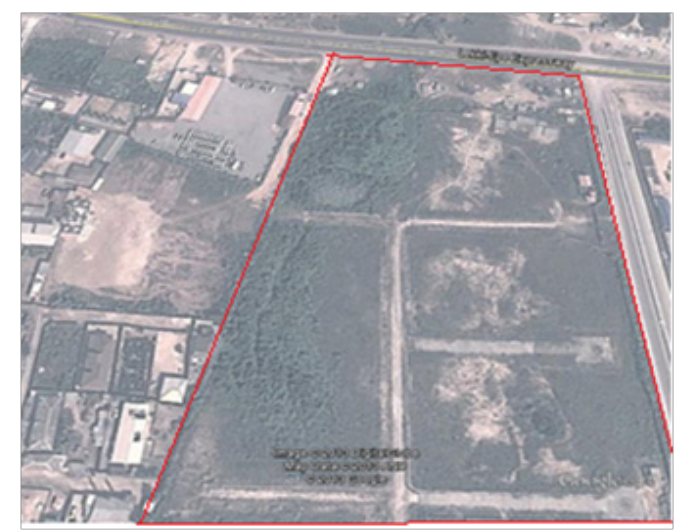

Figure I Aerial photograph of site and adjoining catchment areas.

\section{Climate}

The regime is characterized by tropical rainfall climate with peak rainfall occurring twice a year in the months of May/June and September. It has a distinct dry season with very low rainfall records in the month of November to March of each year. The raining season occurs from April to October of each year with maximum rainfall values usually double peaked one in June/July and the other in September of each year. The rainfall stations in the region include the Meteorological Stations at Lagos, Oshodi, and Apapa meteorological stations. The Gumbel Extreme Value Type I distribution was used on short duration rainfall values of this region to undertake the Intensity 
Duration Frequency analysis (IDF) that was then used to estimate the flood flows for 5, 10, 50, and 100 years of storm rainfall estimate for the estate and the adjourning region contributing to the storm drainage water drained through the estate. The Intensity Duration Frequency analysis undertaken with the rainfall data for $0.4,1.0$, and 3.0 hour rainfall durations are shown in Table 1.

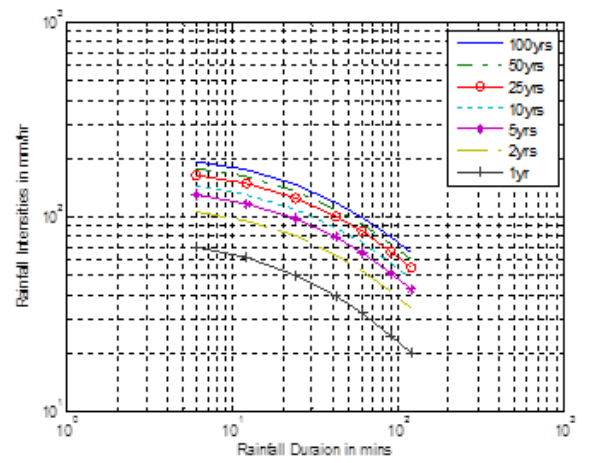

Figure 2 Typical rainfall intensity duration.

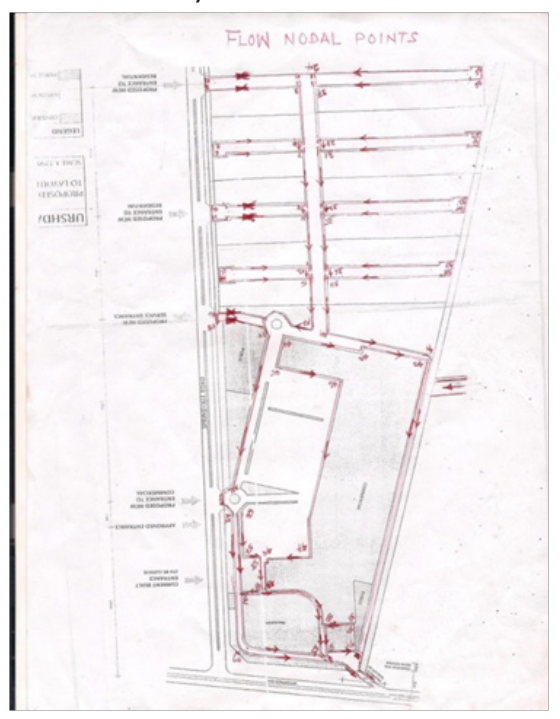

Figure 3 Flow nodal points.

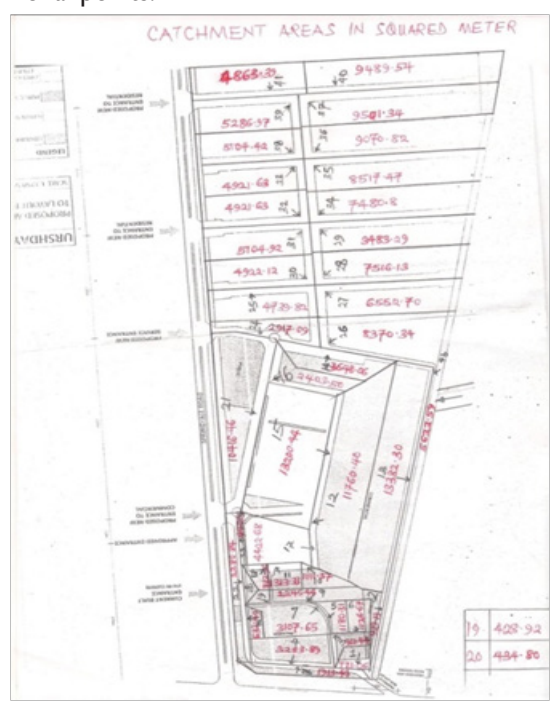

Figure 4 Catchment areas in squared meter.

\section{Vegetation cover}

In its natural state, the vegetation cover is largely shrubs dotted with short palm trees. There is still a thicket of forest to the south west of the estate. Most of the surrounding regions are witnessing urban development processes with the building of structures for residential and commercial purposes. There is ongoing clearing of the surrounding regions for development purposes. This implies the study area will be taken as one with features of developed areas.

Table I Rainfall intensities (mm/hr) for return periods of 5, 10, 25, 50, and $100 y r s$

\begin{tabular}{llll}
\hline \multirow{2}{*}{ Return periods (yrs) } & \multicolumn{3}{c}{ Rainfall durations (hrs) } \\
\cline { 2 - 4 } & $\mathbf{0 . 4}$ & $\mathbf{I}$ & $\mathbf{3}$ \\
\hline 5 & 100 & 70.83 & 43.75 \\
10 & 116.67 & 75.75 & 45 \\
25 & 154.17 & 91.25 & 56.25 \\
50 & 170.83 & 104.17 & 60.32 \\
100 & 182.14 & 125 & 62.5 \\
\hline
\end{tabular}

\section{Sub-surface water and soil permeability}

The level of the pool of water to the northwest of the estate at elevation $3.60 \mathrm{~m}$ provides an indication of the height of the water table. The soil cover is mainly sandy soil with high permeability that allows the easy flow of overland rainfall on the estate to drain from the south to north and from the east to west, with the entire site drained through the pool of water at the north western section of the site to the Lekki Expressway bridge.

\section{Existing storm water infrastructure}

To the east of the estate from Lekki Express way is the road drain of the tarred (developed) road which is higher in elevation to the estate but does not connect to the estate nor drain into the estate. It however drains outside the northern extremely of the estate into the Lekki Express Way bridge to which the estate and the adjourning areas also drain. There is an inlet drainage structure fixed beneath the fence to the western side of the estate. This drainage inlet structure brings water draining the adjourning regions that drains through the estate. Within the Estate, there are existing roads placed on well compacted river dredged sand brought into the estate for road construction purposes. There are 4 existing roads in the estate 3 of them running from east to west and one road runs from south to north. There are three culverts beneath the three east-to-west roads. These culverts are to the west of the estate and they make provision for natural flow of the drainage water from the estate draining from south to north on its way to find an outlet to the bridge on the Lekki Express Way. The sizes of the drains at both sides of the internal roads are square drains varying in size from $35 \mathrm{~cm}$ to $38 \mathrm{~cm}$.

The dimension of the bridge as scaled out from the survey plan provided is as follow:

Cross Section: $8.0 \mathrm{~m}$ width by $3.0 \mathrm{~m}$ depth. Length of the bridge is $24.0 \mathrm{~m}$. In this project work, to design storm water drainage for the estate, rainfall data for meteorological station in the area were collected and the rainfall intensities for various return periods of 5,10 , 25,50 , and 100 years determined. This is presented as an IDF in Figure 2. The sub-catchment areas were determined and the flows from them 
for different return periods calculated. Adjacent areas to the sites that contribute to the storm rainfall flooding the site were also determined. Total flood that flows from the site to the adjacent bridge opening at different return periods was calculated and flood level on the bridge and fence determined at the various return periods. It is therefore in the scope of this work to determine the possible flood extent and to provide the flows that each sewer is required to be designed to carry in order to properly drain the estate in the event of rainfall storm.

\section{Design parameters}

The way and manner in which the water from rain is drained are determined most times by slope, gravity, and the porosity of the ground (soil). It is however controlled or expected to be controlled by man (environmental engineer) in order to have proper use of the water and to prevent hazards. The watershed is expected to be drained into designed and constructed drainages that will conveniently remove the water from the surface in a short time after it has rained and take it through a course/channel where it will not hamper human health and activities. Such a storm water structure as drainage is therefore used to achieve this. The storm water after it has rained will move from all available watersheds to places of lower depth. This if not intended, naturally may pose challenges to human activities and therefore should be controlled. The control however requires the expertise of an environmental engineer in handling storm water through the design of drainages. In designing drainages, watersheds that will channel water to adjoining storm water structures are identified and determined with a good knowledge of the amount of water that is likely to be drained by the watersheds. The knowledge of rainfall and its intensities is therefore important here.

\section{Rainfall}

Rain is the liquid form of the water released to the earth. Rainfall is a climate parameter that affects the way and manner man lives. It affects every facet of the ecological system, flora and fauna inclusive. It is the source of fresh water replenishment for planet Earth. However, too much or too little can mean the difference between prosperity and disaster. According to Viessman W \& Lewis GS. ${ }^{1}$ rainfall is known to be due to the:

a. Cooling of heated moisture-laden air carried by convective current,

b. Lifting of moist horizontal air current over natural barriers such as hills and mountains, or

c. Movement of air masses from high pressure regions and resulting into displacement of warm by colder air.

\section{Rainfall data}

Having a good knowledge of rainfall precedes a good and effective design of storm water facility. The history of the rainfall in a given area helps to a great deal in knowing the trends in the rainfall which in turn helps to know what the future of the rainfall will be like. Data collected from rainfall stations help to know and monitor this trend. Rainfall data are records of rainfall collected with rain gauges and recorded over a long period. Rainfall data are collected for short and long lasting rains. Yarnell ${ }^{2}$ in his 1953 published paper used a series of generalized maps (made of data from about 200 first-orders Weather Bureau stations with complete recording-gauge records) for several combinations of durations and return periods to perform economic and engineering designs that require rainfall frequency data. This led to the installation of hydrologic network of recording gauge in 1940 to supplement both the Weather Bureau recording gauges and the relatively larger number of non-recording gauges. The amount of short duration data has subsequently increased by these additional recording gauges. The first studies covering an extended area which exploited the hydrologic network data were prepared by Weather Bureau Technical Paper No. 24, Parts I and II, prepared for the Corps of Engineers in connection with their military construction program. Results of which showed the importance of the additional data in defining the short-duration rainfall frequency regime in the mountainous regions of the West. Relationships developed and knowledge gained from these studies in the United States was then used to prepare similar reports for the coastal regions of North Africa and several Arctic regions where recording-gauge data were lacking.

For the purpose of defining the depth-area-duration-frequency regime, the Weather Bureau and the Soil Conservation Service in the United States worked together in 1955. Work that had already been performed for the Corps of Engineers, Technical Paper No. 25, was the first paper published under the sponsorship of the Soil Conservation Service, containing a series of rainfall intensity-duration-frequency curves for 200 first-order Weather Bureau stations. It was followed by Technical Paper No. 28, an expansion of Technical Paper No. 24 to longer return periods and durations. After this were published the five parts of the Technical Paper No. 29 series, which cover the region east of $90^{\circ} \mathrm{W}$. Seasonal variation on a frequency basis and area-depth curves were included in this series so that the point frequency values can be transformed to areal frequency.

\section{Rainfall intensities}

The intensity of rainfall depicts the amount of rain that falls in a period of time i.e. the average rainfall depth that falls in specific time duration. Low rainfall and high rainfall intensities mean light and heavy rain respectively. It is measured in $\mathrm{mm} / \mathrm{hr}$. It has been observed that the highest intensity of rainfall is achieved in short-timed rainfall and this contributes mostly to water that causes flood. The occurrence of rainfall cannot be predicted with certainty because rainfall is a random (stochastic) hydrologic event hence, the phenomenon of probability. The distribution of the precipitation over time and space is very complex and irregular. Such irregularity is especially pronounced with respect to the occurrence of the exceptionally heavy storm events. However, it is possible, by the use of rainfall data spanning a long period of time, to estimate the likelihood of the rainfall of a particular magnitude or more occurring within a specified period of time referred to as return period or recurrence interval. The ability to predict the possibility of occurrence of rainfall of a particular magnitude or more which is one of the preliminary stages of storm water drainage design can help individuals, authorities and engineers to plan for such extreme eventualities as flood, drought, landslides, thunderstorms etc. Hence, the study of rainfall is extremely important and should be encouraged in our world of today as it cannot be over emphasized. In order to accurately capture the rainfall and plan adequately with historic events of rainfall, statistical tools of analysis are employed. This helps to forecast or predict future rainfall intensities which are used in the design of hydrologic structures and in water management. These statistical tools have helped in a number of ways in the prediction of future rainfall intensities despite few available data, inhomogeneity of records (e.g. meteorological data may be the result of various incoherent climatological mechanisms), and climatological changes over long periods, which have called for the search for techniques that can efficiently extract the maximum possible content from a set of inadequate rainfall data. Statisticians 
have agreed that floods of small frequency are random variables and that even the highest rainfall intensities are strictly random variables and should be treated as elements of statistics of extremes.

\section{Probability distribution}

Probability distribution is a function representing the probability of occurrence of a random variable. By fitting a distribution to a set of hydrologic data, a great deal of the probabilistic information in the sample can be compactly summarized in the function and its associated parameters. Fitting distributions can be accomplished by the method of moments or the method of maximum likelihood. The interpolation and extrapolation of flood frequencies provide an easy answer on which practicing engineers base their designs. For the purpose of estimation, the Pearson type III, the Gumbel extreme value distribution, and lognormal distribution seem to have found a wider applicability than many other distributions. Ven Te $\mathrm{Chow}^{3}$ has suggested that Gumbel extreme value distribution method of analysis be used for the prediction rainfall intensities.

\section{Pearson type III}

Karl Pearson in 1902 developed the method of moments in which he considered that good estimates of the parameters of a probability distribution are those for which moments of the probability density function about the origin are equal to the corresponding moments of the sample data. He claimed that, if data values are each assigned a hypothetical "mass" which is equal to their relative frequency of occurrence $(1 / \mathrm{n})$ and it is imagined that this system of masses is rota ${ }^{+a} \mathrm{~d}$ about the origin $x=0$, then the first moment of ach observation $x_{i}$ about the origin is the product of its moment $\operatorname{arm}^{x_{i}}$, and its mass, $1 / n$ , and the sum of these moments over all the data is:

$$
\sum_{i=1}^{n} \frac{x_{i}}{n}=\frac{1}{n} \sum_{i=1}^{n} x_{i}=\bar{x}
$$

i.e. the sample mean. Like the centroid of a body, the sample mean is the corresponding centroid of the probability density function and it is:

$$
\mu=\int_{-\infty}^{\infty} x f(x) d x
$$

Equals to their sample values to determine the values of parameters of the probability distribution. Pearson originally considered only moments about the origin, but later it became customary to use the variance as the second central moment,

$$
\sigma^{2}=E(x-\mu)^{2}
$$

and the coefficient of skewness as the standardized third central moment,

$$
\gamma=E(x-\mu)^{3} / \sigma^{3}
$$

To determine second and third parameters of the distribution if required.

The Pearson Type III distribution, also called the three-parameter gamma distribution, introduces a third parameter, the lower bound e, so that by the method of moments, three sample moments (the mean, the standard deviation, and the coefficient $r^{f}$ skewness) can be transformed into the three parameters $\lambda, \beta$, and ${ }^{e}$ of the probability distribution. According to Bobee \& Robitaille, ${ }^{4}$ this is a very flexibl distribution, assuming a number of different shapes as, $\lambda, \beta$, and ${ }^{e}$ vary.
The Pearson system of distributions includes seven types; they are all solutions for $f(x)$ in an equation of the form:

$$
\frac{d(f(x))}{d x}=\frac{f(x)(x-d)}{C_{0}+C_{1} x+C_{2} x^{2}}
$$

Where $d$ is the mode of the distribution (the value of $x$ for which $f(x)$ is a maximum) and $C_{0}, C_{p}$, and $C_{2}$ are coefficients to be determined. When $C_{2}=0$, the solution of above is a Pearson Type III distribution, having a probability density function of the form, $(x)=\frac{\lambda^{\beta}(x-\epsilon)^{\beta} \epsilon^{-\mathrm{e}(\mathrm{x}-\epsilon)}}{\Gamma(\beta)}$. For $C_{i}=C_{2}=0$, a normal distribution is the solution of $0<\beta<1$. Thus, the normal distribution is a special case of the Pearson Type III distribution, describing a non-skewed variable. The Pearson Type III distribution was first applied in hydrology by Foster ${ }^{5}$ to describe the probability distribution of annual maximum flood peaks. When the data are very positively skewed, a $\log$ transformation is used to reduce the skewness.

\section{Gumbel extreme value distribution}

Gumbel's distribution is one of the statistical approaches used in analyzing rainfall data. It is mostly used for this analysis. It is also used to predict hydrological events such as flood. According to Gumbel, the probability of occurrence of an event equal to or longer than value $X_{0}$ is expressed as ${ }^{6}$

$$
P\left(X \geq X_{0}\right)=f(x)=e^{\left\{-\mathrm{e}^{[-\dot{\mathrm{a}}(x-v)]}\right\}}
$$

This equation can be solved for the recurrence interval $T$ and the variate $x$ as follows:

$$
\begin{gathered}
\left.\frac{1}{T}=1-f(x)=1-e^{\{-\mathrm{e}[-\mathrm{a}(x-v)]}\right\} \\
x=U-\frac{1}{\mathrm{a}} \ln \left(\ln \frac{T}{T-1}\right)
\end{gathered}
$$

Now, general frequency equation is

$$
x=\bar{x}+K \cdot S_{x}
$$

where $\mathrm{S}_{x}$ is standard deviation, $\bar{x}$ is the mean for $x$ and $K$ is the frequency factor

$$
\begin{gathered}
\bar{x}=u+\frac{0.5772}{\alpha} \\
S^{2}=\text { variance }=\frac{\pi^{2}}{6 \alpha^{2}}
\end{gathered}
$$

for $\stackrel{\text { S }}{K}$. .

We have;

$$
K=\frac{-\sqrt{ } 6}{\pi}\left(0.5772+\ln \left[\ln \frac{T}{T-1}\right]\right)
$$

Daily maximum rainfall intensity data of various towns were obtained from the measurement available at the various meteorological stations and were subjected to rainfall frequency analysis by applying the Gumbel's distribution method. The steps to estimate the design flood for any return period using Gumbel's distribution was given by 
Ven Te $\mathrm{Chow}^{7}$ and is as presented below:

i. Annual maximum rainfall data for the town was assembled for a period of several years at durations of 15 mins.

ii. The mean, $\bar{x}$ and standard deviation, $S_{x}$ of the rainfall data for the $n$ number of years and for each of these durations, are computed using:

$$
\begin{aligned}
& \bar{x}=\frac{1}{n} \sum_{i=1}^{n} x_{i} \\
& S_{x}=\sqrt{\frac{1}{(n-1)} \sum_{i=1}^{n}\left(\mathrm{x}_{i}-\bar{x}\right)^{2}}
\end{aligned}
$$

The determined mean, $\bar{x}$ and standard deviation, $S_{x}$ values are substituted in (10) and (11) respectively to find $u$ and $u$.

The frequency valu,$K$ is then determined from (12) for the various return periods, ${ }^{T}$ (i.e. 1.01, 2, 5, 10, 20, 50, 100, etc.) and is tabulated.

From $x=\bar{x} d+K . \mathrm{S}_{x}$, the intensity, $\bar{x}$ is determined by substituting calculated values of $\bar{x}, S_{x}$, and the various values of $K$. The results are tabulated in terms of $x$ and intensity $(x)$.

All the generated tables are combined to form a new table using a model of the form

$$
i=\frac{A}{t+B}
$$

the rainfall data for the various return periods can then be used to fit the intensity-duration frequency curves.

The above expression can then be expressed in linear form as

$$
\frac{1}{i}=\frac{t}{A}+\frac{B}{A}
$$

The regression of $\frac{1}{i}$ versus $\mathrm{t}$ will give values of $\mathrm{A}$ and $\mathrm{B}$, first by making $\frac{1}{i}=Y$ and $t=X$, thus $a_{0}=\frac{B}{A}$ and $a_{1}=\frac{1}{A}$, where,

$$
\begin{aligned}
& a_{0}=\frac{\sum Y \sum X^{2}-\sum X \sum X Y}{n \sum X^{2}-\left(\sum X\right)^{2}} \\
& a_{1}=\frac{n \sum X Y-\sum X \sum Y}{n \sum X^{2}-\left(\sum X\right)^{2}}
\end{aligned}
$$

iii. The values of $A$ and $B$ are thus determined and substituted into $(15 a)$ to find the various intensities at any given duration.

iv. It is of great importance to select a design rainfall intensity, which is unlikely to occur during the design life of a hydraulic structure, and as such the difference between the design return period and the estimated life of the structure should be quite large. This is why the return period of hydraulic structure (spillway of dams) is taken very long so as to reduce risk of failure. The use of probability model on the sample of annual maximum rainfall recorded over a given period of time (observation), for a particular area, region or catchment is known as Rainfall Intensity Analysis.

\section{Intensity duration frequency (IDF)}

The intensity duration curve is a graphical representation of the probability that a given average rainfall intensity will occur. It is a plot of rainfall intensities against rainfall duration. The curve shows the possibility of intensity occurring once every given year (return period) e.g. 1-yr return period, 2-yr return period, 5-yr return period, etc. the curve is presented for a given place based on history of rainfall in that place. One can then check the possible intensity of rainfall for a reoccurrence possibility and duration e.g. 10-year 15-min storm. It is normally plotted with the derived coefficients, $A$ and $B$ from the Gumbel's distribution.

\section{Materials and methods}

\section{Design of urban drainage}

The method for determining the rates of storm water runoff for urban drainage design is dependent on rainfall intensity, run off, topography, and development. Several approaches have been used for this. Among the more commonly used are:

(i) The empirical formulas

(ii) The rational method

(iii) Rainfall-runoff relation studies

(iv) Hydrograph (unit \& synthetic unit hydrograph) methods, and

(v) Computer models.

\section{The rational method}

The Rational Method is a traditional method for stormwater drainage design because of its simplicity. It is used to determine the layout and preliminary sizing of a system. The design from Rational Method can be refined by dynamic routing of the flow hydrographs through the system. The application of the Rational Method is as described below:

\section{Basic formulations}

The idea behind the Rational Method is that the runoff at the outlet of a catchment for a spatially and temporally uniform rainfall intensity $I$ which continues indefinitely will increase until the time of concentration, ${ }^{t} c$, when the whole catchment is contributing flows to the outlet. The peak runoff is given by the following expression:

$$
Q_{p}=240 * C i A
$$

Where $Q_{p}=$ peak (maximum) rate of runoff in $\mathrm{m}^{3} / d$

$C=$ average runoff coefficient (dimensionless)

$i=$ average rainfall intensity in $\mathrm{mm} / \mathrm{hr}$

$A=$ catchment area in ha

For a catchment consisting of $m$ sub-catchments of areas $A$ ( $\mathrm{km}^{2}$ ), each of which have different runoff coefficients $C_{j}$, the peak runoff at the outlet of drainage is given as:

$$
Q_{p}=240 * i * \sum_{j=1}^{m} C_{j} A_{j}
$$

According to the Euro code, the Rational Method should not be used on areas larger than $1.5 \mathrm{~km}^{2}$ because of the assumptions of homogeneity of rainfall and equilibrium conditions at the time of peak 
flow. Hence, the overall catchment should be subdivided into smaller catchments and including the effect of routing through drainage channels. The same consideration shall also be applied when ground gradients vary greatly within the catchment.

\section{Runoff coefficient}

$C$ is a constant value that is specific for given surface types. Judgement and experience on the part of the designer determines the proper selection of the runoff coefficient for a given design. The value of $C$ depends on the nature of the surface of catchment as impermeability, slope and retention. It also depends on the characteristics and conditions of the soil, vegetation cover, the duration and intensity of rainfall, and the antecedent moisture conditions, etc. Mostly, a value of $C=0.9-1.0$ is commonly used in developed urban areas. In less developed areas, $C$ values are picked from Table 2 in the appendix for corresponding surface type and checks be put in place if catchment area surface will not change upon foreseen further development. It is important for designer to investigate and ascertain the ground conditions before adopting an appropriate runoff coefficient. Designers may consider it appropriate to adopt a more conservative approach in estimation of $C$ values for smaller catchments where any consequent increase in cost may not be significant. However, for larger catchments, the designers should exercise due care in the selection of appropriate $C$ values in order to ensure that the design would be fully cost-effective. For steep natural slopes or areas where a shallow soil surface is underlain by an impervious rock layer, a higher $C$ value of $0.4-0.9$ may be applicable.

Rainfall intensity $i$ is the average rainfall intensity selected on the basis of the design rainfall duration and return period. The design rainfall duration is taken as the time of concentration $t_{c}$.

Table 2 Sub-catchment areas at site and flows for different return periods

\begin{tabular}{|c|c|c|c|c|c|}
\hline $\mathbf{S} / \mathbf{N}$ & $\begin{array}{l}\text { Catchment areas } \\
\left(\mathrm{m}^{2}\right)\end{array}$ & $\begin{array}{l}\text { Flows @ } 9=5 y r s \\
\left(\mathrm{~m}^{3} / \mathrm{s}\right)\end{array}$ & $\begin{array}{l}\text { Flows @ } @=10 y r s \\
\left(\mathrm{~m}^{3} / \mathrm{s}\right)\end{array}$ & $\begin{array}{l}\text { Flows @ } @=50 y r s \\
\left(\mathrm{~m}^{3} / \mathrm{s}\right)\end{array}$ & $\begin{array}{l}\text { Flows @ } 9=100 y r s \\
\left(\mathrm{~m}^{3} / \mathrm{s}\right)\end{array}$ \\
\hline I & 773.06 & 0.019327 & 0.022548 & 0.033015 & 0.035201 \\
\hline 2 & 929.13 & 0.023228 & 0.0271 & 0.039681 & 0.042308 \\
\hline 3 & 911.44 & 0.022786 & 0.026584 & 0.038925 & 0.041502 \\
\hline 4 & 3283.89 & 0.082097 & 0.095783 & 0.140247 & 0.149532 \\
\hline 5 & || $80.3 \mid$ & 0.029508 & 0.034427 & 0.050408 & 0.053745 \\
\hline 6 & 1126.67 & 0.028167 & 0.032862 & 0.048117 & 0.051303 \\
\hline 7 & 3107.65 & 0.077691 & 0.090642 & 0.13272 & 0.141507 \\
\hline 8 & 632.49 & 0.015812 & 0.018448 & 0.027012 & 0.0288 \\
\hline 9 & 2245.44 & 0.056136 & 0.065494 & 0.095897 & 0.102246 \\
\hline 10 & 1111.37 & 0.027784 & 0.032416 & 0.047464 & 0.050606 \\
\hline II & 1313.33 & 0.032833 & 0.038307 & 0.056089 & 0.059802 \\
\hline 12 & 11760.4 & 0.29401 & 0.343021 & 0.502257 & 0.53551 \\
\hline 13 & 13382.3 & 0.334558 & 0.390328 & $0.57 \mid 525$ & 0.609363 \\
\hline 14 & 3648.06 & 0.091202 & 0.106405 & 0.1558 & 0.166114 \\
\hline 15 & 13200.44 & 0.330011 & 0.385024 & 0.563758 & 0.601082 \\
\hline 16 & 2403.5 & 0.060088 & 0.070104 & 0.102647 & 0.109443 \\
\hline 17 & 4422.68 & 0.110567 & 0.128999 & 0.188882 & 0.201387 \\
\hline 18 & 782.96 & 0.019574 & 0.022837 & 0.033438 & 0.035652 \\
\hline 19 & 428.92 & 0.010723 & 0.012511 & 0.018318 & 0.019531 \\
\hline 20 & 434.8 & 0.01087 & 0.012682 & 0.018569 & 0.019799 \\
\hline 21 & 10416.46 & $0.2604 I 2$ & 0.303822 & $0.44486 I$ & $0.4743 \mid 4$ \\
\hline 22 & 2280.84 & 0.057021 & 0.066526 & 0.097409 & 0.103858 \\
\hline 23 & 444.75 & 0.011119 & 0.012972 & 0.018994 & 0.020252 \\
\hline 24 & 2917.09 & 0.072927 & 0.085084 & 0.124582 & 0.13283 \\
\hline 25 & 4739.82 & 0.118496 & 0.138249 & 0.202426 & 0.215828 \\
\hline 26 & 8370.34 & 0.209259 & $0.244 \mid 42$ & 0.357476 & $0.38 \mid 143$ \\
\hline 27 & 6552.7 & 0.163818 & 0.191126 & 0.279849 & 0.298377 \\
\hline 28 & 7516.13 & 0.187903 & 0.219227 & 0.320995 & 0.342247 \\
\hline 29 & 3483.29 & 0.087082 & 0.101599 & 0.148763 & 0.158612 \\
\hline
\end{tabular}




\begin{tabular}{llllll}
\multicolumn{6}{l}{ Table Continued } \\
\hline $\mathbf{S} / \mathbf{N}$ & $\begin{array}{l}\text { Catchment areas } \\
\left(\mathbf{m}^{2}\right)\end{array}$ & $\begin{array}{l}\text { Flows @ T=5yrs } \\
\left(\mathbf{m}^{3} / \mathbf{s}\right)\end{array}$ & $\begin{array}{l}\text { Flows @ T=10yrs } \\
\left(\mathbf{m}^{3} / \mathbf{s}\right)\end{array}$ & $\begin{array}{l}\text { Flows @ T=50yrs } \\
\left(\mathbf{m}^{3} / \mathbf{s}\right)\end{array}$ & $\begin{array}{l}\text { Flows @T=100yrs } \\
\left(\mathbf{m}^{3} / \mathbf{s}\right)\end{array}$ \\
\hline 30 & 4922.12 & 0.123053 & 0.143566 & 0.210211 & 0.224129 \\
31 & 5104.92 & 0.127623 & 0.148898 & 0.218018 & 0.232453 \\
32 & 4921.63 & 0.123041 & 0.143552 & 0.210191 & 0.224106 \\
33 & 4921.63 & 0.123041 & 0.143552 & 0.210191 & 0.224106 \\
34 & 7480.8 & 0.18702 & 0.218196 & 0.319486 & 0.340638 \\
35 & 8517.47 & 0.212937 & 0.248433 & 0.36376 & 0.387843 \\
36 & 9070.82 & 0.226771 & 0.264573 & 0.387392 & 0.41304 \\
37 & 9501.34 & 0.237534 & 0.27713 & 0.405778 & 0.432644 \\
38 & 5104.42 & 0.127611 & 0.148883 & 0.217997 & 0.23243 \\
39 & 5286.97 & 0.132174 & 0.154208 & 0.225793 & 0.240742 \\
40 & 9489.54 & 0.237239 & 0.276786 & 0.405275 & 0.432106 \\
41 & 4863.39 & 0.121585 & 0.141853 & 0.207703 & 0.221454 \\
42 & 1913.44 & 0.047836 & 0.05581 & 0.081718 & 0.087128 \\
43 & 5622.59 & 0.140565 & 0.163997 & 0.240127 & 0.256025
\end{tabular}

\section{Time of concentration}

$t_{f}$ is the time required for water to flow from the farthest point in the catchment to its outlet (i.e. to the inlet of drain). It is the time for a catchment to be completely rid of its surface water. For an urban drainage system,

$$
\begin{aligned}
& t_{c}=t_{0}+t_{f} \\
& t_{f}=\sum_{j=1}^{m} \frac{L_{j}}{V_{j}}
\end{aligned}
$$

$t_{f}=$ flow time

$L_{j}=$ length of $j^{\text {th }}$ reach of drain

$V_{j}=$ flow velocity in $j^{\text {th }}$ reach of drain

$t_{0}=$ time of concentration of a natural catchment (min.)

The inlet time, or time of concentration of a natural catchment normally range from 5 to 10 mins for high intensity areas with closely spaced street inlets, 10-20mins for well-developed areas within relatively flat slopes, and 20-30mins for residential areas with widely spaced inlets.

\section{Minimum velocities}

$V$ is the slowest rate at which water is required to flow in the sewer in order not to deposit grits that accompany the storm water. Design speed is therefore expected to be more than this minimum speed. Commonly used minimum speed is $0.9-1.0 \mathrm{~m} / \mathrm{s}$. The minimum speed is normally determined from the Manning's equation,

$$
V=\frac{1}{n} R^{2 / 3} S^{1 / 2}
$$

Where, $\mathrm{V}=$ =velocity, $\mathrm{m} / \mathrm{s} \mathrm{R}=$ hydraulic radius, $m$ and, $S=$ slope, $m / m$

\section{Design procedure}

The storm-water sewer is laid out on the site drawing as in Figure 1. Arrows show direction from of flow.

i. Manholes are located at $100 \mathrm{~m}$ for $300-600 \mathrm{~mm}$ sewers, and $120 \mathrm{~m}$ for larger sewers. These are indicated as nodal points in Figure 1. Limits of drainage areas tributary are established at every manhole.

ii. Areas of the drainage subareas are then determined. This is achieved from the drawing and/or on site.

iii. The rainfall intensity is determined for the area.

iv. Run-off coefficient(s) also determined. Here, $80 \%$ impervious (0.86) for street and $20 \%$ pervious $(0.26)$ for slopped grass land were used.

Flow, $Q$ is then determined from the equation: $Q=C i A$

The tabulation as in columns 3 through 6 on Table 1 for the various return periods is made with the flow in each sewer determined.

The same is done to determine the flow in the drains that convey the water outside of the estate. The possible flow and levels in the bridge adjacent the site were presents on Tables 3, Table 4 .

Table 3 The flows adjacent areas that contribute to storm rainfall flow flooding the site

\begin{tabular}{lllll}
\hline $\begin{array}{l}\text { Catchment areas } \\
\left(\mathbf{m}^{2}\right)\end{array}$ & Flow @ T=5yrs $\left(\mathbf{m}^{3} / \mathbf{s}\right)$ & Flow @ T=10yrs $\left(\mathrm{m}^{3} / \mathbf{s}\right)$ & Flow @ T=50yrs $\left(\mathrm{m}^{3} / \mathbf{s}\right)$ & Flow @T=100yrs $\left(\mathrm{m}^{3} / \mathbf{s}\right)$ \\
\hline 20620 & 0.5155 & 0.601434 & 0.880629 & 0.938932 \\
\hline
\end{tabular}


Table 4 Total flood flow from the site to the adjacent bridge opening at different return periods

\begin{tabular}{lllll}
\hline $\begin{array}{l}\text { Total area } \\
\left(\mathbf{m}^{2}\right)\end{array}$ & $\begin{array}{l}\text { Total flow @ T=5yrs } \\
\left(\mathbf{m}^{3} / \mathbf{s}\right)\end{array}$ & $\begin{array}{l}\text { Total flow @ T=l Oyrs } \\
\left(\mathbf{m}^{3} / \mathbf{s}\right)\end{array}$ & $\begin{array}{l}\text { Total flow @ T=50yrs } \\
\left(\mathbf{m}^{3} / \mathbf{s}\right)\end{array}$ & $\begin{array}{l}\text { Total flow @T=100yrs } \\
\left(\mathbf{m}^{3} / \mathbf{s}\right)\end{array}$ \\
\hline 234955.8 & 5.873895 & 6.853073 & 10.03437 & $10.6987 \mid$
\end{tabular}

\section{Presentation of results}

\section{Major and minor flows}

The minor flows of $1: 5$ and $1: 10$ and the major of $1: 50$ and $1: 100$ were calculated and tabulated in Table 2.

\section{The flood lines}

The flood lines at the bridge for different return periods, $\mathrm{T}$ are given in Table 5.

Table 5 The flood levels on bridge and fence at the various return periods

\begin{tabular}{lll}
\hline $\begin{array}{l}\text { Return } \\
\text { period T } \\
\text { (in years) }\end{array}$ & $\begin{array}{l}\text { Flood level at } \\
\text { the bridge }(\mathbf{m})\end{array}$ & $\begin{array}{l}\text { Estimated flood } \\
\text { level at the fence } \\
(\mathbf{m})\end{array}$ \\
\hline 5 & 4.45 & 4.803 \\
10 & 4.569 & 4.963 \\
30 & 4.85 & 5.34 \\
50 & 4.946 & 5.47 \\
100 & 5.021 & 5.563 \\
\hline
\end{tabular}

Using the slope of the water surface within the bridge, the flood lines at the reference point on the northern edge of the fence of the estate were calculated and given on Table 5 for return periods 5,10 , 50 and 100 years.

\section{Outlets}

Two recommended internal drains to the north western side of the estate serve as outlet drains. This is shown in Figure 1.They should empty into a culvert by the fence of the estate near the proposed lay by exit to convey water outside the estate.

\section{Attenuation and storm water treatment}

The drainage plan for the new layout drains under gravity into the bridge inlet outside the estate with no need for storm water detention structures. Since industrial wastes are not envisaged, there is no need to install wastewater treatment plant before storm water drains outside the estate in Figure 5, Figure 6.

\section{Conclusions and recommendations}

The expected flood flows for Return Periods of 5, 10, 50, and 100 years and the flood levels and the placement of drains have been provided for the proposed new layout. The existing external bulk infrastructure to which the flood water drains from the estate and the adjourning areas is the bridge on the Lekki Expressway. Our design work has been done using the detailed dimension of this bridge, the flows obtained from the catchment areas and the flood level obtained on the bridge for 30-year Return Period. Using this information, the flood values and the flood levels at a specified position by the fence have been provided on Table 5 of this report. From the Survey plan, the bottom of the bridge was obtained as $3.39 \mathrm{~m}$ level. The flood levels are taken with this $3.39 \mathrm{~m}$ at the bridge as the reference point. The bottom of the fence is at $3.40 \mathrm{~m}$ level, according to the Survey Plan. Our reference point for the flood level within the estate is a point (BM) on the fence of the estate as shown in Figure 7, Figure 8 with its base at $3.40 \mathrm{~m}$. These values are given in Table 6, Figure 9, Figure 10, Figure 11, Figure 12.

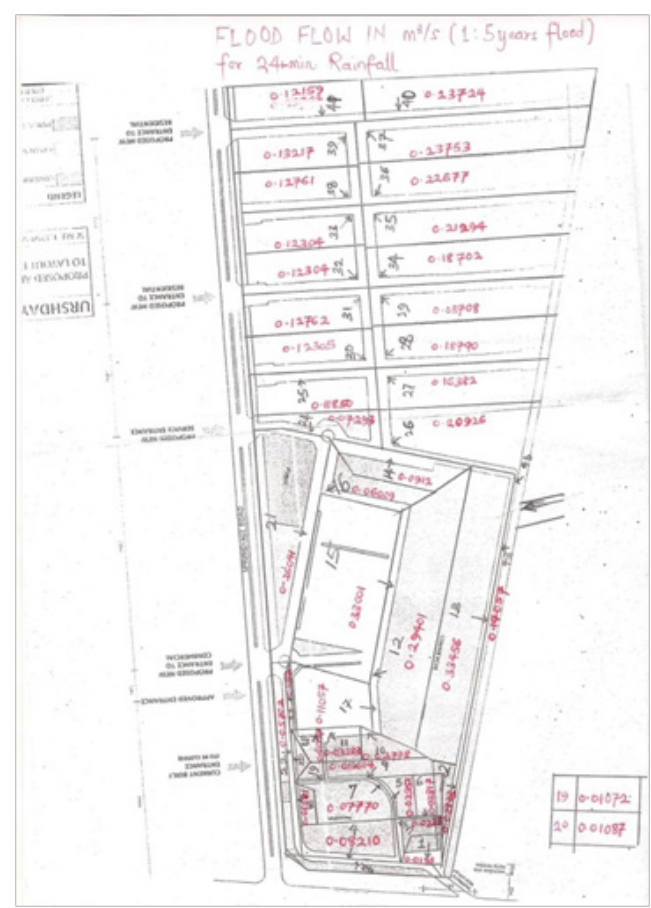

Figure 5 Flood flow for the catchment for 5-yr Return Period.

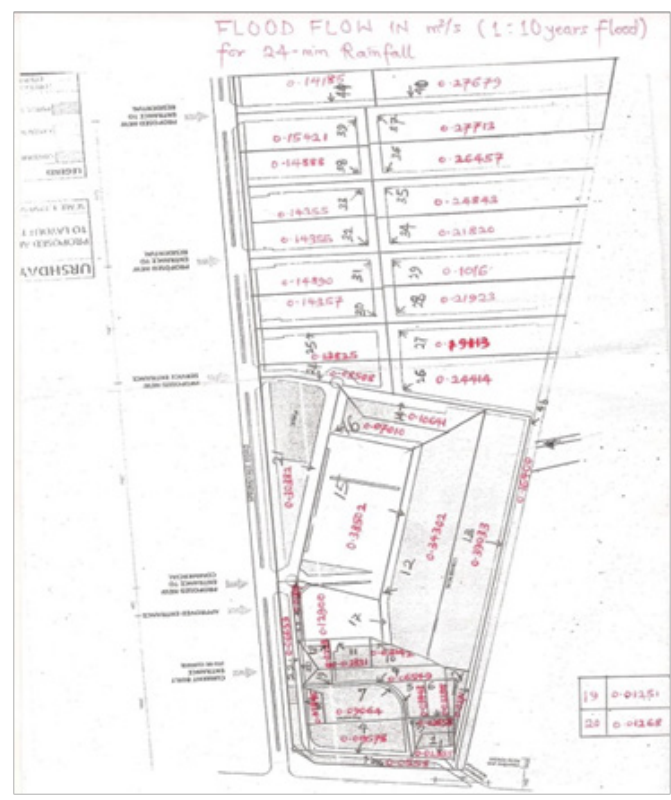

Figure 6 Flood flow for the catchment for 10-yr Return Period. 


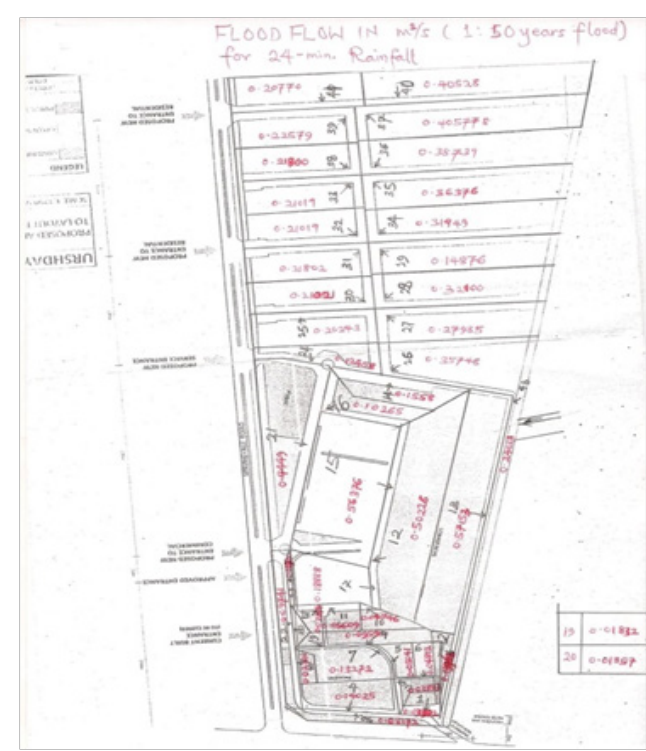

Figure 7 Flood flow for the catchment for 50-yr Return Period.

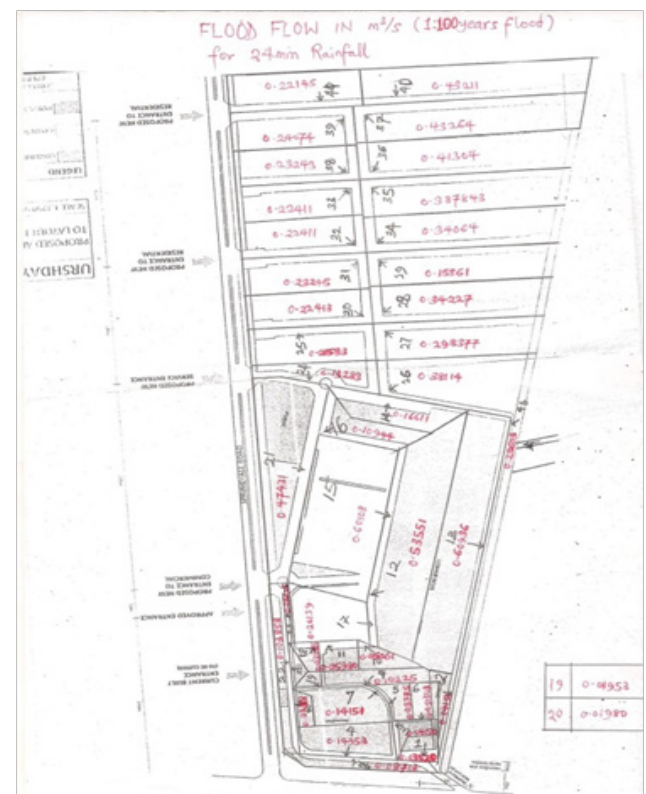

Figure 8 Flood flow for the catchment for 100-yr Return Period.

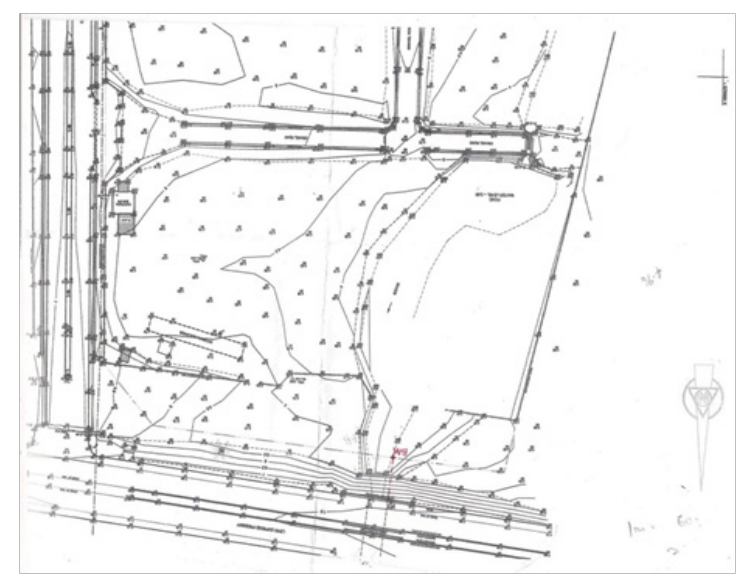

Figure 9 Location of the level at bottom of fence.

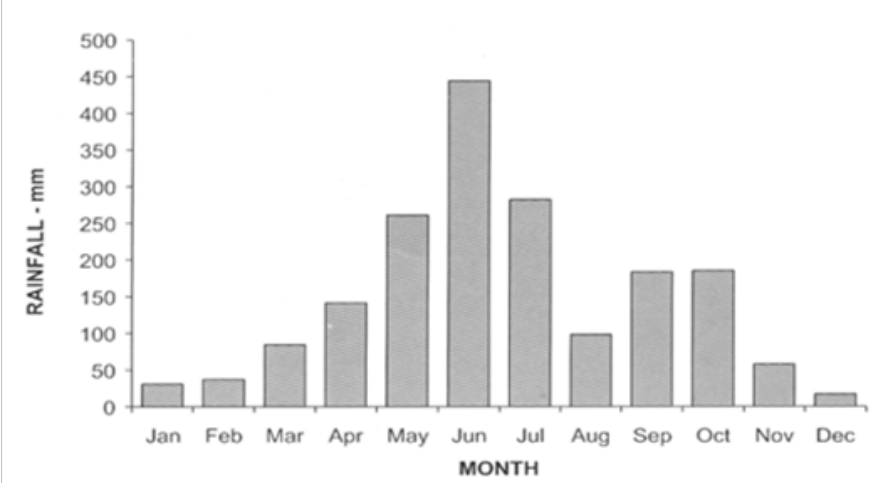

Figure 10 Average monthly rainfall at Lagos station (1943-1994).

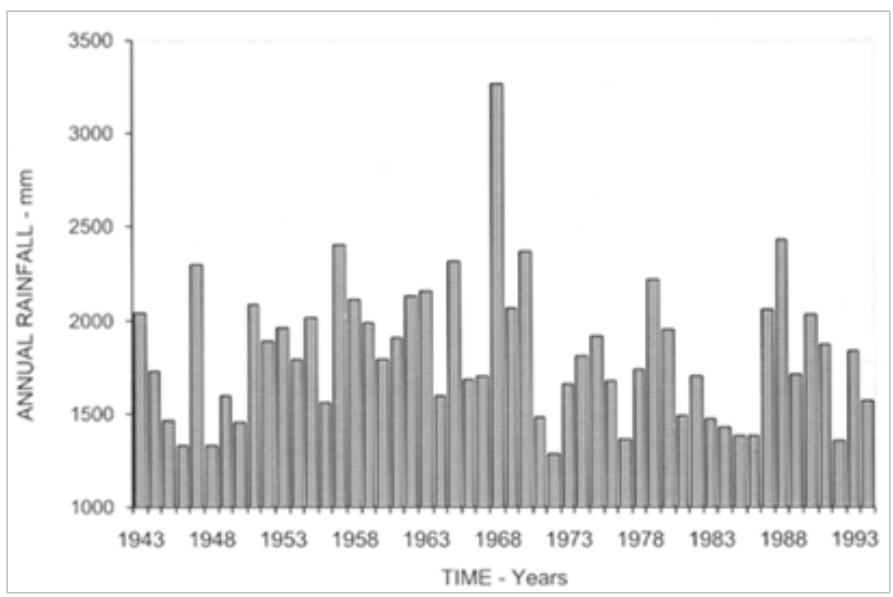

Figure I I Total annual rainfall at Lagos station (1943-1994).

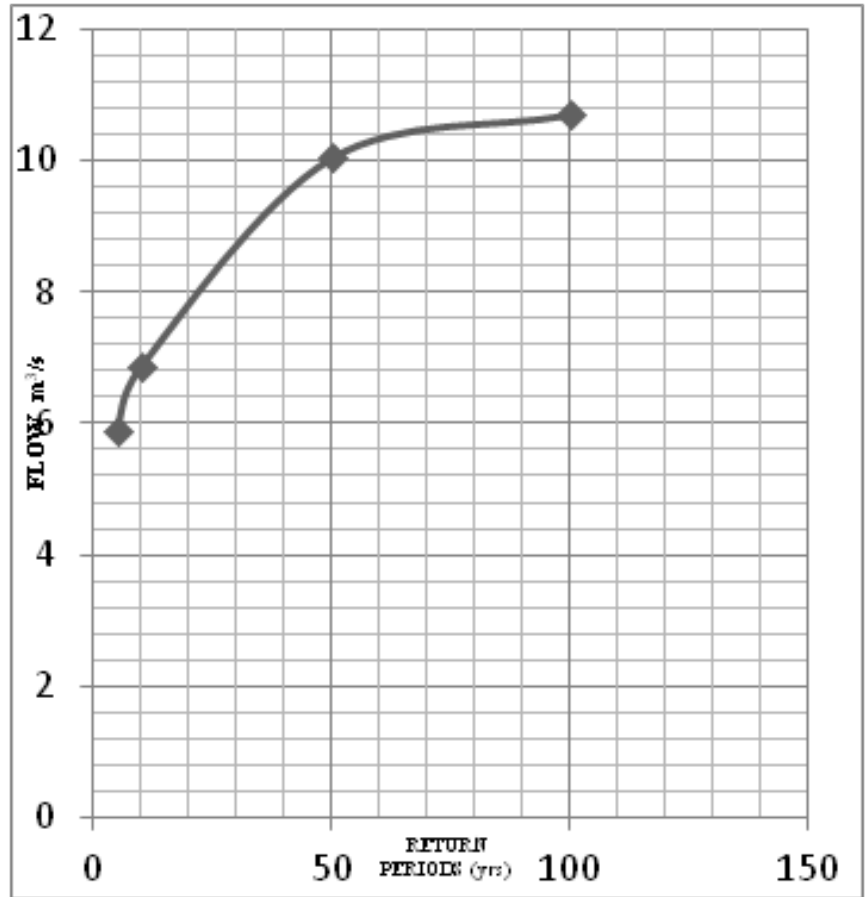

Figure 12 Intensity duration frequency (IDF). 
Table 6 Maximum annual short duration rainfal

\begin{tabular}{llll}
\hline \multirow{2}{*}{ Duration (yrs) } & \multicolumn{3}{l}{ Rainfall(mm) } \\
\cline { 2 - 4 } & $\mathbf{0 . 4 ( h r s )}$ & $\mathbf{I . 0}(\mathbf{h r s})$ & $\mathbf{3 . 0}(\mathbf{h r s})$ \\
\hline 1963 & 0.5 & 1.82 & 2.9 \\
1964 & 0.7 & 2.83 & 3.29 \\
1965 & 0.57 & 2.1 & 2.24 \\
1966 & 0.86 & 3.13 & 3.89 \\
1967 & 1.5 & 1.63 & 3.49 \\
1968 & 1.78 & 2.95 & 3.75 \\
1969 & 0.62 & 1.89 & 3.17 \\
1970 & 1.52 & 3.05 & 3.87 \\
1971 & 1.01 & 2.05 & 4.44 \\
1972 & 0.86 & 2.64 & 6.07 \\
1973 & 0.97 & 2.61 & 2.96 \\
1974 & 1.38 & 2.11 & 2.69 \\
1975 & 0.79 & 2.35 & 3.1 \\
1981 & 0.78 & 3.24 & 3.39 \\
1983 & 1.06 & 1.06 & 1.4 \\
\hline
\end{tabular}

\section{Acknowledgement}

None.

\section{Conflict of interest}

The authors declare there is no conflict of interest.

\section{References}

1. Viessman W, Lewis GL. Introduction to Hydrology. Addison Wesley Longman; 1996.
2. Yarnell DL. Rainfall Intensity-Frequency Data. Miscellaneous Publication No. 204, Washington DC: US Dept of Agriculture. 1935;1-69.

3. Chow VT. Open-Channel Hydraulics. New York: McGraw-Hill; 1959.

4. Bobee BB, Robitaille R. The use of Pearson type III and Log-Pearson type III distributions revised. Wat Resour Res. 1997;13(2):427-443.

5. Foster HA. Theoretical frequency curves and the application to engineering problems. Am Soc Civil Engineers Trans. 1974;87:142-203.

6. Shaw EM. Hydrology in Practice. UK: Van Nostrand Reinhold. 1983.

7. Chow VT. Applied Hydrology. New York: McGraw-Hill. 1988.

8. American Association of State Highway and Transportation Officials. Highway Drainage Guidelines. Chapter 7: Hydraulic Analysis for the Location and Design of Bridges. AASHTO, Washington DC. 2007.

9. American Association of State Highway and Transportation Officials. Model Drainage Manual. Chapter 2: Legal Aspects, AASHTO, Washington DC. 2005.

10. American Society of Civil Engineers. Design and Construction of Urban Stormwater Management Systems. ASCE Manuals and Reports of Engineering Practice No. 77, WEF Manual of Practice FD-20. New York, NY. 1992;1-2154.

11. American Iron and Steel Institute. Modern Sewer Design. Washington DC: American Iron and Steel Institute. 1990;1-348.

12. Government of the Hong Kong Special Administrative Region. Stormwater Drainage Manual (with Eurocodes incorporated) Planning. Design and Management. 2013.

13. Izzard CF. Hydraulics of Runoff from Developed Surfaces. Proc Highway Research Board. 1946;26:129-150.

14. Johnson FL, Chang FM. Drainage of Highway Pavements. Hydraulic Engineering Circular 12. Washington DC: FHWA-TS-84-202, Federal Highway Administration. 1984;1-155.

15. Lever WF. Manual for Highway Storm Water Pumping Stations. Washington DC: FHWA-IP-82-17, Federal Highway Administration. 1982. 